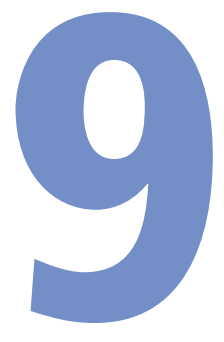

\title{
Geodetic Observations and Global Reference Frame Contributions to Understanding Sea-Level Rise and Variability
}

\author{
Geoff Blewitt, Zuheir Altamimi, James Davis, \\ Richard Gross, Chung-Yen Kuo, Frank G. Lemoine, \\ Angelyn W. Moore, Ruth E. Neilan, Hans-Peter Plag, \\ Markus Rothacher, C.K. Shum, Michael G. Sideris, \\ Tilo Schöne, Paul Tregoning, and Susanna Zerbini
}

\subsection{Introduction}

\subsubsection{Purpose and Scope}

Geodetic observations are necessary to characterize highly accurate spatial and temporal changes of the Earth system that relate to sea-level changes. Quantifying the long-term change in sea-level imposes stringent observation requirements that can only be addressed within the context of a stable, global reference system. This is absolutely necessary in order to meaningfully compare, with submillimeter accuracy, sea-level measurements today to measurements decades later. Geodetic observations can provide the basis for a global reference frame with sufficient accuracy. Significantly, this reference frame can be extended to all regional and local studies in order to link multidisciplinary observations and ensure long-term consistency, precision, and accuracy. The reference frame becomes the foundation to connect observations in space and time and defines the framework in which global and regional observations of sea-level change can be understood and properly interpreted. Geodetic observations from in situ, airborne, and spaceborne platforms measure a variety of quantities with increas-

Understanding Sea-Level Rise and Variability, 1st edition. Edited by John A. Church, Philip L. Woodworth, Thorkild Aarup \& W. Stanley Wilson. () 2010 Blackwell Publishing Ltd. 
ing accuracy and resolution and address interdisciplinary science problems, including global sea-level change. In this chapter we identify critical geodetic requirements to meet the rigorous scientific demands for understanding sealevel rise and its variability, and thus contribute to improving its prediction. In particular, we stress the need for the continuity of the geodetic observational series that serve basic research, applications, and operational needs.

\subsubsection{Geodesy: Science and Technology}

Geodesy is concerned with the measurements of geometry, Earth orientation, and gravity and the geoid.

- Geometry: this refers to changes of the position of the Earth with respect to a system of quasars through time, and, in the context of sea level, changes of the surface geometry of the Earth; that is, the variations in time and space of ocean surfaces and ice covers, and of horizontal and vertical deformations of the solid Earth. Unfortunately, geodesy currently is not able to measure the vertical deformations of roughly $71 \%$ of the Earth's surface that is the ocean floor.

- Earth orientation: this is measurement of fluctuations in the orientation of our rotating planet relative to the stars, commonly divided into precession, nutation, polar motion, and changes in Earth rotation, which defines and monitors the transformation between the celestial (quasar system) and terrestrial (Earth-fixed) reference frames. Earth rotation is described by the Euler-Liouville equations describing the motion of a rather general Earth, including the solid (non-rigid) body, oceans, and atmosphere.

- Gravity and the geoid: this refers to variations in space and time of the Earth's gravity field, usually expressed as anomalies of the gravity vector, the geoid and the gravity gradient tensor. Gravity and the geoid are mathematically derived from the equations of motion of natural and artificial satellites (in post-Newtonian formulation). For more detail on these general concepts see Beutler (2005).

Each of these three "pillars of geodesy" (Rummel et al. 2005) relate to sea level, and so sea-level has always been a traditional focus of geodetic theory and practice. The surface geometry of the solid Earth defines the ocean bottom surface, which can provide a reference for measuring relative sea-level change (e.g. by tide gauges), and is essential to understanding the impacts of sea-level change (e.g. ground subsidence in Venice or Lagos or New Orleans). Sea-level changes associated with mass redistribution (e.g. melting polar ice sheets and glaciers) affect Earth rotation and polar motion. In static equilibrium, the sea surface follows the shape of the geoid. Moreover, mass redistribution associated with sea-level change also changes the shape of the geoid and the ocean bottom surface, and hence sea level (Figure 9.1). Thus geodesy is fundamental to a comprehensive understanding of sea-level variation; in fact, sea-level variation cannot be understood outside the context of geodesy.

Geodesists specialize in acquiring, analyzing, and interpreting spacebased, ground-based, and airborne geodetic measurements that are important for 


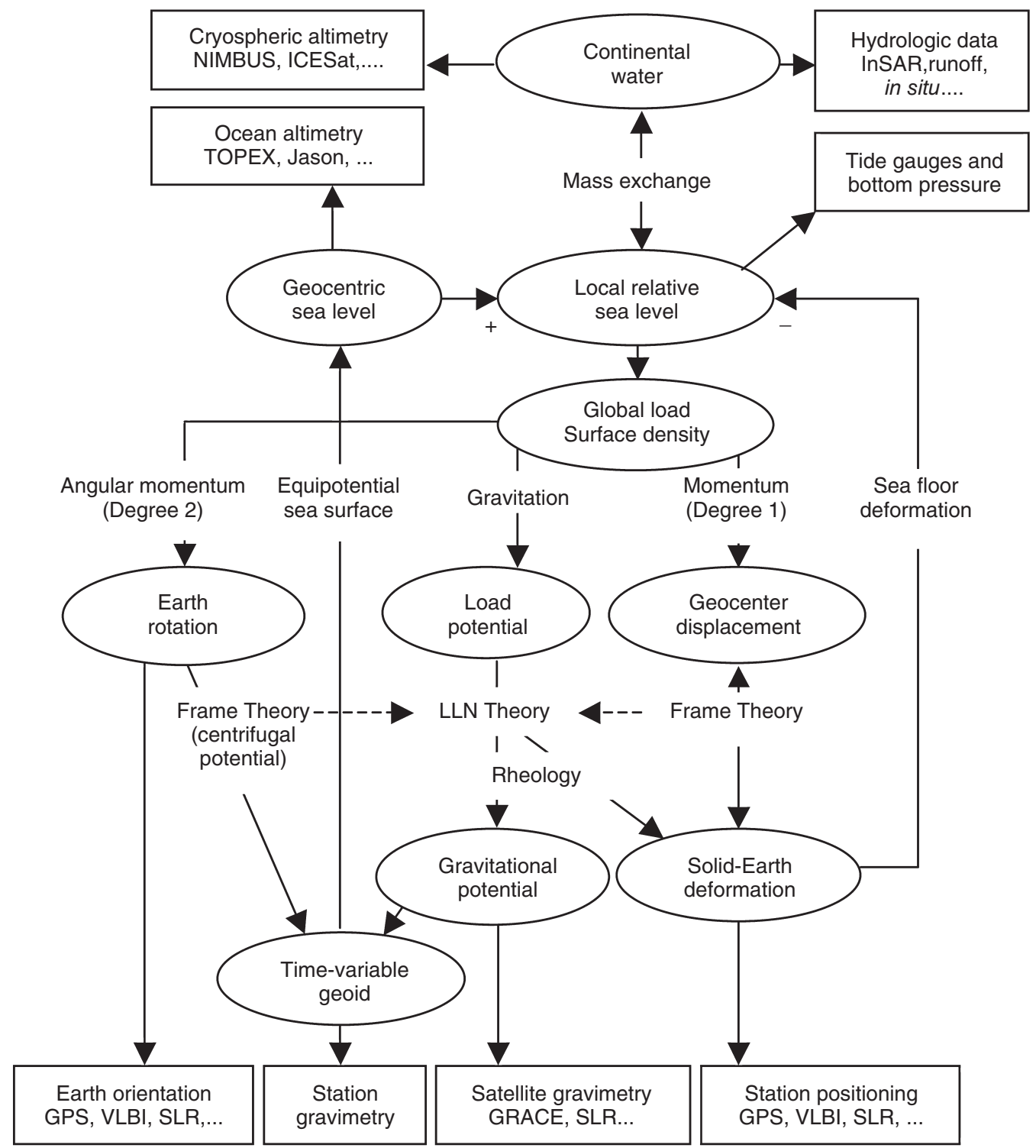

Figure 9.1 A model that incorporates self-consistency of the reference frame (Blewitt 2003), loading dynamics, passive ocean response, and Earth rotation. Closed-form inversion solutions have been demonstrated (Blewitt and Clarke 2003), thus setting the scene for data assimilation. Note that everything is a function of time, so "continental water" in its most general sense would include the entire past history of ice sheets responsible for post-glacial rebound. Arrows indicate the direction toward the computation of measurement models, phenomena are in round boxes, measurements are in rectangles, and physical principles label the arrows. GPS, Global Positioning System; GRACE, Gravity Recovery and Climate Experiment; ICESat, Ice, Cloud, and Land Elevation Satellite; InSAR, interferometric synthetic aperture radar; LLN, load Love number; SLR, satellite laser ranging; VLBI, very-long-baseline interferometry. 
understanding sea-level changes. Geodetic observations and analysis contribute to an understanding of Earth processes relevant to sea-level studies. These include but are not limited to:

- hydrology and continental water storage;

- mass balance of ice sheets, ice caps, and glaciers;

- glacial isostatic adjustment (GIA);

- tides of the solid Earth and the oceans and their dissipations, and, to a lesser extent, poles and atmosphere;

- ocean circulation and ocean-bottom pressure change;

- crustal motion associated with plate tectonics, earthquakes, and volcanoes, including coastal deformations and anthropogenic subsidence;

- weather and climate, atmospheric structure, water vapor, and space weather.

Fundamental to understanding these processes is the creation and maintenance of a terrestrial reference frame (TRF) and its tie to inertial space, the celestial reference frame (CRF). The TRF and CRF provide the universal standard against which the Earth is measured; it is the foundation on which solid Earth science disciplines rest. Deficiencies in the accuracy or continuity of the TRF/CRF system limit the quality of science it can support. Observable variations in the TRF/ $\mathrm{CRF}$ - geocenter motion and rotation irregularities - are themselves primary signals in the science of Earth change. In the context of this book, control of the reference frame over long periods of time may be a primary limiting factor for understanding sea-level change, land subsidence, crustal deformation, and icesheet dynamics.

\subsubsection{Global Geodetic Observing System (GGOS)}

Many modern geodetic techniques require a globally distributed infrastructure for collecting observations. The International Association of Geodesy (IAG) has established a variety of technique-specific scientific services since the late 1980s to facilitate global coordination and to ensure highly accurate and reliable geodetic products to support geoscientific research. And so, in the past, geodetic research concentrated on individual measurement techniques and processes, rather than on the added value that can be drawn from their integration. The Global Geodetic Observing System (GGOS) (Drewes 2005; Plag 2005) is an important new component of the IAG, and intends to give these fundamental components of geodesy a new quality and dimension in the context of Earthsystem research by integrating them into a coordinated and collective observing system with utmost precision in a well-defined and reproducible global terrestrial frame. GGOS acts as an umbrella for the IAG services, and coordinates with these scientific services to ensure the development and availability of a global geodetic infrastructure and resulting science, and to identify potential gaps in services, or where new services are required to meet user needs. GGOS will aim to integrate 
the combination of geometric, gravimetric, and rotational data in data analysis and data assimilation, and the joint estimation or modeling of all the necessary parameters representing the difference components of the Earth system. For GGOS to meet its objectives, it must combine the greatest measurement precision (a relative precision of 0.01 parts per billion $=10^{-11}$ ) with utmost consistency in space, time, and applied data modeling, and with stability spanning decades. This is a key focus of GGOS.

\subsubsection{Geodetic Observations as a Foundation for Assessing and Interrelating Sea-Level Measurements and Uncertainties}

The rotation vector of the Earth, usually called the angular velocity vector and referred to the Earth-fixed system, is characterized by its length, the angular velocity (which in turn is directly derived from the length of day), and by two polar coordinates, which may be chosen as the angular distances of the Earth's rotation axis from the Earth's figure axis (in two orthogonal directions); these angles are called polar motion components or simply polar coordinates. This rotation vector of the solid Earth exhibits minute but complicated changes of up to several parts in $10^{8}$ (corresponding to a variation of several milliseconds in the length of the day), and about one part in $10^{6}$ in the orientation of the rotation axis relative to the solid Earth's figure axis (corresponding to a variation of several hundred milli-arcseconds in polar motion). The principle of conservation of angular momentum requires that changes in the rotation vector of the solid Earth must be manifestations of (1) torques acting on the solid Earth or (2) changes in the mass distribution within the solid Earth, which alter its inertia tensor. Angularmomentum transfers occur between the solid Earth and the fluid regions (the underlying liquid metallic core and the overlying hydrosphere and atmosphere) with which it is in contact; concomitant torques are due to hydrodynamic or magneto-hydrodynamic stresses acting at the fluid/solid Earth interfaces. Thus, as the angular momentum of the hydrosphere changes because of sea-level rise and ice-sheet volume variations, the angular momentum of the solid Earth will change, thereby giving rise to changes in the solid Earth's rotation vector. Similarly, the Earth's gravitational field will change as the ocean-bottom pressure changes, and, under the principle of the conservation of angular momentum, the Earth's rotation will change as the oceanic angular momentum varies due to fluctuations in the ocean-bottom pressure and velocity fields. Such variations are detectable from space-geodetic observations.

Satellite altimetry (laser and radar) measures the changes of the sea level, ice elevations, and lake/river levels with an accuracy of $1 \mathrm{ppb}$ with respect to the center of mass of the Earth (Chelton et al. 2001; Schutz et al. 2005; Crétaux and Birkett 2006). Satellite altimetry measurements of the time-varying sea level, when assimilated into oceanic general circulation models along with other remotely sensed and in situ measurements, provide improved estimates of the three-dimensional oceanic temperature, salinity, and velocity fields. Altimetry measurements by 


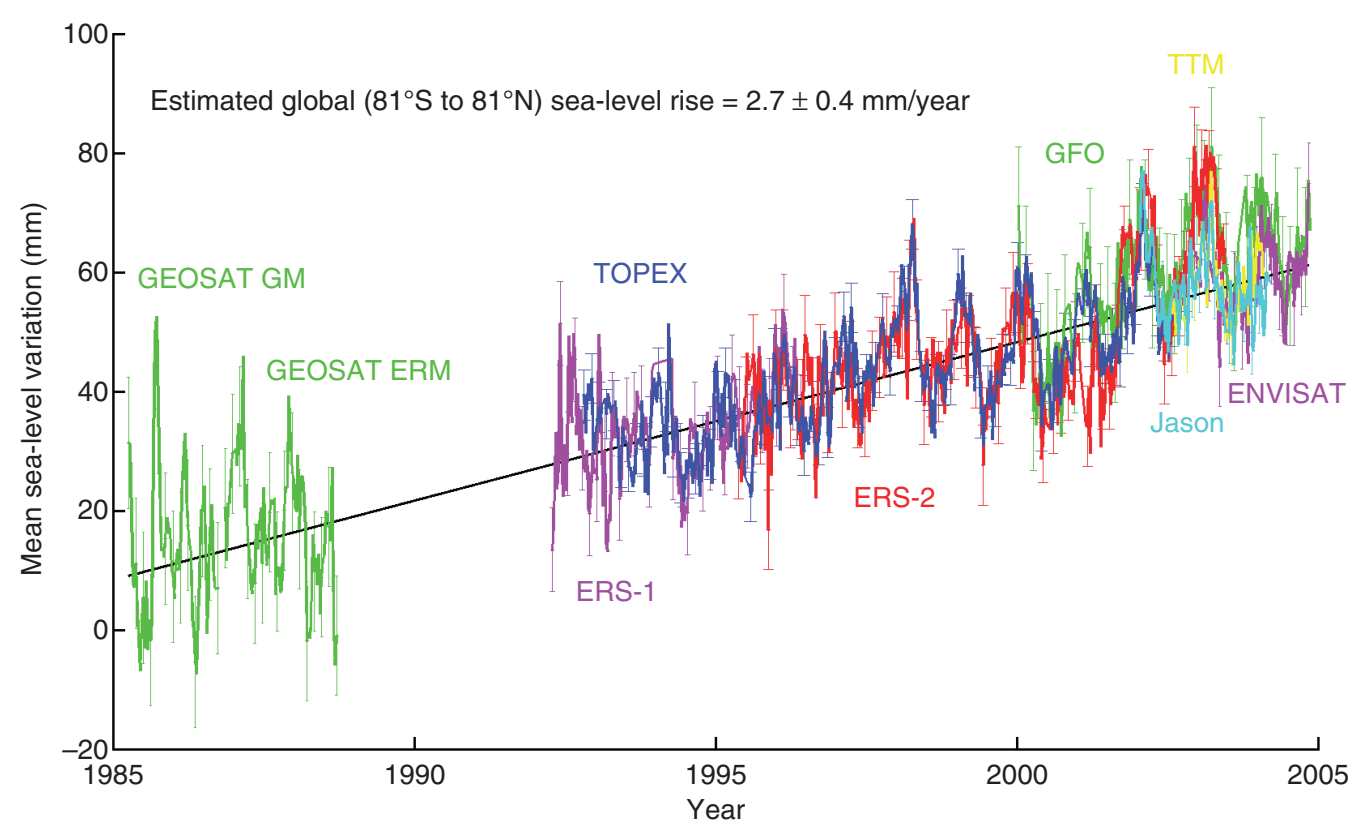

Figure 9.2 Change in global mean sea level over 19852004 as measured by multiple satellite altimetry missions (Kuo et al. 2006). Connecting observations from different

satellite missions in a meaningful way is nontrivial and a precise, common reference frame for time periods spanning decades is essential.

TOPEX/Poseidon and its follow-ons, Jason-1 and -2, allow the determination of the sea surface height (Figure 5.5) which varies due to both thermal expansion of sea water and changes in ocean water mass arising from changes in polar ice cap, mountain glacier mass, and groundwater storage. Longer-term altimeter observations from multiple missions are clearly needed in the future and with sufficient overlap (e.g. multiyear) to permit the separate missions to be properly interconnected (e.g. Figure 9.2 from an early combination study by Kuo et al. 2006). Connecting observations from these sequential satellite missions (and often times non-overlapping missions) in a meaningful way is non-trivial, but critically essential for assessing long-term changes in sea level or other Earth process. The need to interconnect satellite mission observations in a common, precise terrestrial reference frame over decades is a driving justification for attention to the global geodetic infrastructure, and its maintenance and improvement.

Advances in the measurement of gravity with modern free-fall methods have reached accuracies of $10^{-9} \mathrm{~g}\left(1 \mu \mathrm{gal}\right.$ or $\left.10 \mathrm{~nm} / \mathrm{s}^{2}\right)$, allowing the measurement of effects of mass changes in the Earth interior or the geophysical fluids (ocean and atmosphere loading), as well as the measurement of height changes of approximately $3 \mathrm{~mm}$ relative to the Earth center of mass (Forsberg et al. 2005). Measurements of the temporal gravity field from space demonstrated by the Gravity Recovery and Climate Experiment (GRACE) satellite mission (Tapley et al. 2004) and in situ terrestrial measurements (absolute and superconducting 
Figure 9.3 Global mean sea level determined through the theory of loading by GPS measurements of Earth's shape (Blewitt and Clarke 2003) compared with direct measurements by TOPEX/ Poseidon corrected for steric effects, and terrestrial hydrology, as inferred by mass conservation. gravimeters) provide a new global instrument for measuring mass changes of the fluid envelopes of the Earth system as well as viscoelastic response of the Earth's mantle to deglaciation, which are directly relevant to the measurement of global sea-level change. Satellite missions, such as GRACE and the European Space Agency's (ESA's) Gravity Field and Steady-State Ocean Circulation Explorer (GOCE) mission, make gravitational field observations that are sensitive to temporal and spatial variations in the Earth's mass distribution, and can be used to investigate sea-level rise and ice-sheet volume changes. The Earth's gravitational field is not sensitive to the thermal expansion of sea water; observations of the gravitational field can be used in concert with sea-level change observations to separate the change due to thermal expansion or contraction from that due to oceanic mass changes, which helps to quantify the extent to which global warming due to climate change is sequestered in the oceans (Watts and Morantine 1991).

In addition, geometrical geodesy (which today primarily implies Global Navigation Satellite Systems (GNSSs), such as the US Global Positioning System (GPS)), can directly measure displacements of the Earth's surface with a precision higher than $1 \mathrm{~mm} /$ year, and thus can characterize change in the Earth's shape, and the land component of relative sea-level change as measured by tide gauges. Changes in the Earth's shape can also be inverted for surface mass redistribution (Blewitt and Clarke 2003) and thus can infer time variations in the shape of the geoid that defines the sea surface in static equilibrium. Blewitt and Clarke (2003) demonstrated this technique to infer the seasonal variation in the mass component of sea-level change with no direct measurements of the ocean, independently confirming published results from TOPEX/Poseidon (corrected for steric effects), and results inferred from terrestrial hydrology (Figure 9.3). GPS is also used to position satellite altimeters in space relative to GPS stations on land, and thus the reference frame of Earth surface measurements can be made compatible with the

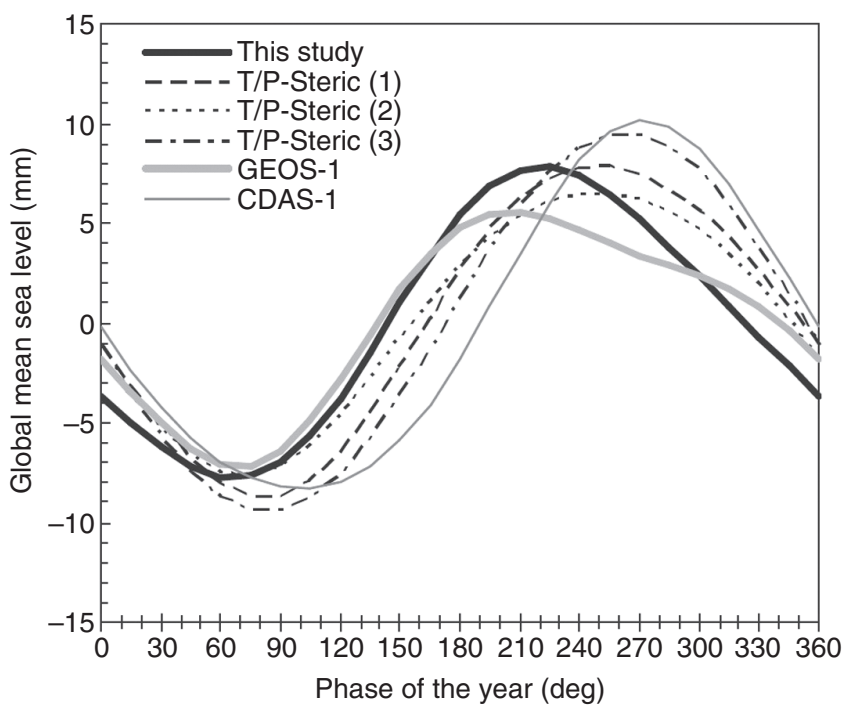


frame of sea-surface measurements by having all observations in one reference frame.

While most geodetic observations are "point-based", interferometric synthetic aperture radar (InSAR) provides two-dimensional mapping views of Earth surface changes. The spatial resolution provided by InSAR is increasingly important for studies of deformation before, during, and after an earthquake, volcanic hazards, groundwater movements, and ice-sheet dynamics. InSAR relies on repeated imaging of a given geographic location by airborne or satellite radar platforms (such as the ESA's European Remote Sensing satellite-1 and -2 (ERS-1/-2) missions and the Canadian Radarsat 1/2 missions). With two complex radar images of the same area one can generate an interferogram as the difference in phase of the return from each pixel. The phase differences are sensitive to topography and any change in position of the imaged area. These effects can be separated using either an independent topographic data set or an additional interferogram that does not include any surface deformation; that is, with negligible temporal separation between repeat passes. A map can be constructed from the two data sets that shows the component of surface motion in the line-of-sight direction of the sensor. Interferograms can detect displacements of a few millimeters.

InSAR can measure two-dimensional glacier or ice-stream flow rates directly related to the computation of ice mass balance, which is one of the major uncertainties of sea-level change. InSAR can also contribute to the measurement and modeling of vertical land motion critical for accurate sea-level observations from coastal tide gauges.

These geodetic data sets (Earth rotation, satellite altimetry, gravity, GNSS/ GPS, InSAR) provide a powerful suite of tools for investigating the causes and consequences of sea-level change.

\subsection{Global and Regional Reference Systems}

\subsubsection{Introduction}

One of the largest sources of error today in the global characterization of longterm sea-level variation is uncertainty in the TRF. For example, a $2 \mathrm{~mm} /$ year error in relative velocity between the mean surface of the Earth and the Earth system's center of mass can result in an error as large as $0.4 \mathrm{~mm} /$ year in mean global sealevel variation as determined by satellite altimetry (Kierulf and Plag 2006). The effect on local sea level can be even larger and of opposite sign (Figure 9.4). A scale-rate error of $0.1 \mathrm{ppb} /$ year would map into a sea-level rate of $0.6 \mathrm{~mm} /$ year. These frame biases are comparable to or larger than the contributions to secular sea-level change of thermal expansion, and mass exchange with the Greenland and Antarctic Ice Sheets. It cannot be understated how important it is to make further progress in improving the TRF for studies of global change in sea level. 


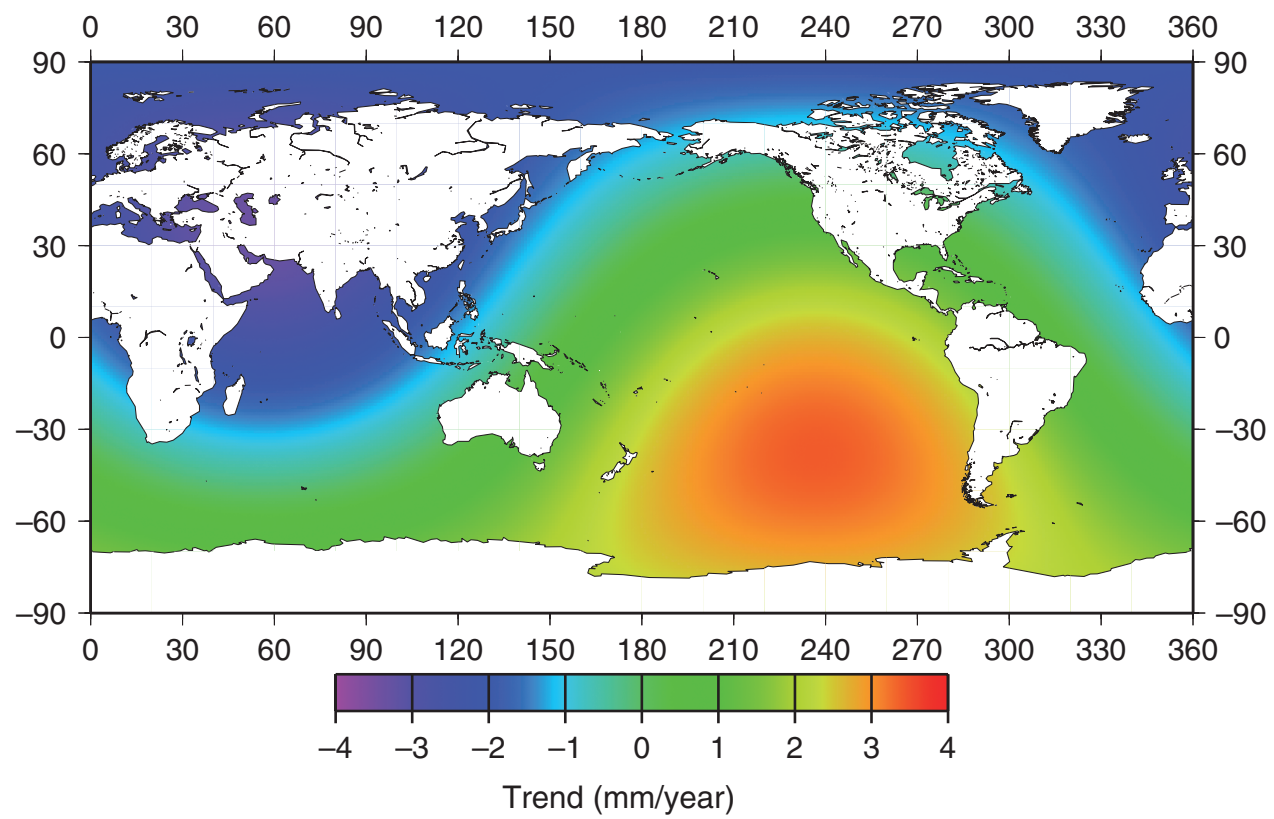

Figure 9.4 Simulated effect on sea-level error inferred by satellite altimetry caused by an error in realizing the reference frame. This example shows the effect of differences between two frames realized by the International GNSS Service (IGS): one is IGb00, which is aligned with ITRF2000; the other is the frame of the IGS precise point positioning products (Kierulf and Plag 2006). The difference in the $(x, y, z)$ motion of the geocenter of these two frames is $(-1.5,-2.2,-2.1) \mathrm{mm} /$ year. The difference in sea level ranges from -3 to $+3 \mathrm{~mm} /$ year, with a mean-sea-level error of $0.4 \mathrm{~mm} /$ year caused by asymmetric distribution of the ocean. (From Plag 2006.)

Yet reference frames (apart from the importance of the vertical motions of the ocean bottom) are perhaps the least understood or appreciated component of the methods that connect observations to global measures of sea-level change.

This section focuses on two main points. First, it is important to provide the scientific community a basis for understanding reference frames and their importance in the study of sea-level change. This requires careful definition of terms with this exacting application in mind. Second, there is a complex interaction through models between the reference frame and observations that can be used to assess sea-level variation. This interaction will be explored to identify where weaknesses lie. Recommendations regarding improving the reference frame for sea-level research will result. To take this discussion beyond abstract concepts, specific investigations that underscore the difficulties arising from uncertainty in the reference frame, at both the regional and global scales, will be cited.

This section should emphasize the importance of reference frames in characterizing regional and global sea-level change, and result in a better understanding of what needs to be done to reduce the level of errors introduced by complex interaction between observations, models, and reference frames. 


\subsubsection{Terminology: Defining a Reference System and Frames}

Toward understanding sea-level variation, geodetic measurements are used to determine the position of the sea surface and ocean bottom in a globally consistent Terrestrial Reference System (TRS). The TRS must contain physical models (see e.g. Figure 9.1) that are gravitationally self-consistent in order to connect geometrical measurements to (1) the dynamics of the primary geodetic satellite orbits (e.g. GNSS/GPS), (2) the orbits of sensor satellites (e.g. altimeter satellites, gravity missions, InSAR), and (3) the equipotential ("level") surfaces that define sea level in static equilibrium. The connection to gravity is essential for "height variation" to be physically meaningful, allowing for interpretation within the context of a gravitationally self-consistent model. Such a system requires rigorous modeling of Earth rotation, which in turn affects the Earth's gravity field from the perspective of a terrestrial frame co-rotating with the Earth (e.g. centrifugal forces), as well as from the rotationally forced redistribution of mass in both the solid Earth response and the oceanic response (e.g. pole tides). Moreover, gravitational variation caused by mass redistribution changes the Earth's geometrical surface (including the ocean bottom) in a predictable way through surface loading models. Finally, the TRS must be connected to the "real world" through a TRF, where physical points have assigned coordinates that are consistent with the mathematical definition and physical models of the TRS.

The TRS is much more than a coordinate system. Generally accepted terms related to TRS are defined in Kovalevsky et al. (1989):

1 the ideal TRS is a mathematical, theoretical system;

2 the conventional TRS then is the sum of all conventions, parameters, constants (e.g. $\mathrm{GM}, \mathrm{c}$, etc.) that are necessary to realize the TRS;

3 a conventional TRF: any TRF is conventional by definition because of the use of (2) and in the meantime the TRF is a realization of the TRS.

The distinction must be clear between the TRS and the TRF; that is, the latter is the realization of the former, and for that conventions are required. Considering a TRS as only a coordinate system can lead to misunderstandings and potential misinterpretations. These concepts can represent a barrier to understanding the significance of geodetic observations of sea level in non-geodetic communities, which is why so much emphasis is placed on the reference system in this chapter (and observational techniques and Earth models are discussed in detail in other sections of this book). In this section the components of a TRS are defined and explained at a conceptual level with the non-geodesist in mind, avoiding the more technical and rigorous definitions that are fundamental to geodesists, for whom the definitive document today is McCarthy and Petit (2003), and references therein.

The relative positions of points in space can be completely specified by coordinates within a defined coordinate system. Coordinates actually overspecify the problem; the parameters that need to be defined are origin, orientation, and scale 
of the coordinate system (and their evolution in time), which are implicitly defined by assigning arbitrary coordinate values to points. For global-scale geodesy, it is convenient to choose a Cartesian coordinate system, from which transformations into other coordinate systems can be mathematically defined (for example, a conventional ellipsoidal system such as WGS-84, the World Geodetic System 1984 of the GPS). It is useful therefore when thinking about familiar systems such as WGS-84 to think of the underlying Cartesian system as being more fundamental. For example, inside a GPS receiver the GPS positioning problem is solved in a Cartesian system $(x, y, z)$, and the position in WGS-84 (longitude, latitude, height) is calculated and displayed only as the very last step.

However, it is important to note that a TRS should not be confused with a coordinate system or a reference frame, both of which are realizations of the reference system. In general, a TRS comprises three main components, as follows.

First is a datum, which can be an ideal definition of the origin, orientation, and scale of the coordinate system, and their evolution in time. For example, the coordinates of a physical point can be defined as part of the datum definition (such as fixing the height of a benchmark for the height datum, or defining the longitude of a fiducial mark at Greenwich). Of particular relevance to sea level is the choice of vertical datum. Tide gauges measure sea level with respect to a tidegauge datum that is only useful locally and not suitable for global studies. An attempt to measure the relative height between local tide-gauge datums does not provide an effective global solution to this problem, though it may be useful for some regional studies. For the modern TRS, the use of local fiducial marks (e.g. "fundamental stations") to define the datum is no longer used, except perhaps in some average sense over the entire reference frame (see the third item below). Thus the vertical datum is secondary, in that it must be defined in terms of the global datum parameters. Now the origin can be ideally defined as the center of mass of the Earth system, and the scale can be defined by the International System of Units (SI) meter as realized by atomic clocks together with the conventional speed of light. Observations of satellite orbits can be used to infer an origin at the center of mass of the Earth system, which connects the geometric Earth's surface to the gravity field. This is especially important for global-scale observation of sea-level change. The center of mass of the Earth system can be considered a unique, static equipotential surface (surrounding an infinitesimal point) that can be chosen as the vertical datum. However, such a choice of vertical datum, being so far away from the actual sea surface, requires an ability to position points at the Earth's surface with respect to the Earth center of mass with high accuracy. This in turn requires a stable scale, and scale plays a very practical role in this realization of the vertical datum for sea-level studies, even though it is not directly related to equipotential surfaces as such. In order to realize a practical global vertical datum it is convenient to link the gravity field to the geometry of the Earth's surface (land and sea), a natural choice of TRS origin and scale. Such a capability has only recently become possible with the advent of space geodesy, through which the origin can be realized through the dynamics of the satellite orbits by satellite laser ranging (SLR) and GNSS, and through which scale can be 
stabilized through observations of distant quasars using very-long-baseline interferometry (VLBI). The orientation of the modern TRS is such that the $z$-axis points towards the Earth's pole at some reference epoch (since the Earth's pole actually moves at a detectable level from day to day), with the $x$ - and $y$-axes defining a conventional equatorial plane. The $x$-axis is chosen to define the meaning of Prime Meridian (zero longitude, which is no longer defined by the fiducial mark at Greenwich and actually lies approximately $200 \mathrm{~m}$ away), and the $y$-axis completes the right-handed frame, thus completing the datum definition. Among the datum parameters, the choice of orientation of the three axes is of least consequence to the problem of sea-level variation.

Second are the conventions of the reference system, which typically specify how to compute the coordinates of a point on the Earth's surface at an arbitrary time, given the epoch coordinates of that point at some initial time (the reference epoch). This transformation typically corresponds to a physical motion model (including, for example, solid Earth tides). The epoch coordinates here generally refer to parameters that are required to initialize the motion model, for example, initial position coordinates and velocity coordinates. As the motion models improve (by theory and/or experiment), so the reference system conventions might be updated from time to time. The datum can be considered part of the conventions, although it is so important that it can be useful to consider it separately.

Third is a reference frame, which is a list of epoch coordinates of a set of physical reference points (sometimes called benchmarks), derived from observations and conventions in a way that is self-consistent with the first and second components, above. This procedure is known as reference-frame realization. A reference system can have several associated reference frames derived by different realizations specific to observation systems or different spans of observations. Typically there will be a unique reference frame that is recommended as the definitive frame, and commonly such a definitive frame represents a synthesis of various observational types, using as much data as possible. Hence the definitive frame requires updating from time to time. Note that in practice, it is the reference frame that implicitly defines the origin, orientation, and scale of the reference system. If, for example, the ideal orientation cannot be realized uniquely by observations alone, one can expect different reference frame realizations to produce coordinates that might differ quite significantly. This problem can be mitigated by frame alignment of subsequent realizations to some initial frame to ensure a level of consistency. For some applications, maintaining consistency in this manner is of primary importance. For other applications, it is less desirable to maintain consistency than to achieve the highest accuracy. The latter demands progressively improving the frame's accuracy in terms of how well it is aligned with the ideal datum, such as improving the alignment of the origin with the center of mass of the Earth system. This might arise as a result of an improvement in geodetic data analysis models, or upgrades to the physical models in the TRS itself. As frames are updated in this manner, this often requires the complete reanalysis of data and its interpretation within the new system. This is the reality 
faced by sea-level investigations, for which the entire time series of sea level will, in general, be changed as improvements are made to the frame.

The International Terrestrial Reference System (ITRS) was developed by the geodetic community under the auspices of the International Earth Rotation and Reference Systems Service (IERS), a service of the IAG, for the most demanding scientific applications. The most accurate realizations of the ITRS are called the International Terrestrial Reference Frame (ITRF) where multitechnique geodetic solutions are rigorously combined to form the ITRF. There is no single ITRF, but rather a series of updated and improved versions. The versions are identified by the year associated with the date of last data used in the analysis, and should not be confused with the date of applicability. The most recent versions are ITRF1997, ITRF2000, and ITRF2005 (Altamimi et al. 2007). Generally, as time progresses, there is less need for frequent updates, because more time may be needed to make significant improvements through the addition of new data and improved models. However, to satisfy increasing accuracy requirements, the ITRF will continue to be updated to incorporate more advanced models for the time-dependent reference coordinates, and must be updated after large earthquakes. These successive frames provide a common reference to compare observations and results from different locations. The four main geodetic techniques used to compute accurate coordinate include: GPS, VLBI, SLR, and Doppler Orbitography Radiopositioning Integrated by Satellite (DORIS). Since the tracking network equipped with the instruments of those techniques is evolving and the period of data available increases with time, the ITRF is constantly being updated.

\subsubsection{Geodetic Techniques for Realizing the ITRF}

For the last few decades, continuous improvement of space geodesy techniques, in terms of technology and modeling of their observations, has drastically improved our ability to determine the terrestrial reference frame toward reaching the $1 \mathrm{~mm}$ accuracy level on the surface of the continents (but certainly not on the ocean bottom). The fundamental techniques through which these measurements have been acquired include GNSS satellites (GPS, Global Orbiting Navigation Satellite System (GLONASS) and future Galileo), SLR, VLBI, and DORIS. Changes in the surface geometry are measured via microwaves using radar altimetry (e.g. Fu and Chelton 2001), using lasers (e.g. ICESat, the National Aeronautics and Space Administration's (NASA's) Ice, Cloud, and Land Elevation Satellite; Schutz et al. 2005), or InSAR (Seeber 2003). The orbits of the satellites making these surface change observations must be computed as precisely as possible from precise geodetic observations using GPS, SLR, and/or DORIS, in a coherent and stable reference frame. For example, for TOPEX/Poseidon and Jason-1, orbits are computed for these radar altimeter satellites to a radial accuracy of $1-2 \mathrm{~cm}$. This accuracy can be verified through intercomparison of orbits computed by independent geodetic techniques (Haines et al. 2004; Luthcke et al. 2003). 
Today, the geodetic techniques that contribute to the realization of the ITRF are organized as scientific services within the IAG:

- IERS;

- International GNSS Service (IGS), formerly the International GPS Service (Dow et al. 2005);

- International VLBI Service (IVS) (Schlüter et al. 2002);

- International Laser Ranging Service (ILRS) (Pearlman et al. 2002);

- International DORIS Service (IDS) (Tavernier et al. 2006).

These scientific services, as well as the gravity field services, now within the umbrella of the International Gravity Field Service (IGFS; http://www.igfs.net/), and a possible future altimetry service, are integral components of GGOS (Rummel et al. 2005). The GGOS focus on a collective effort acknowledges that closer cooperation and understanding among the IAG services can bring significant improvements to the ITRF (http://www.ggos.org).

Each of the observational techniques has unique characteristics. VLBI connects the ITRF to the celestial reference frame and is important for realizing the scale accurately. SLR is the satellite technique that is used to locate the center of mass of the Earth system, and so defines the origin. GPS primarily contributes to the number of sites that define ITRF (densification of ITRF), and to monitoring polar motion precisely. GPS, DORIS, and SLR are used to position Earth orbiting satellites in ITRF, and GPS is used to position points and their velocities on the Earth's land and sea surfaces, such as benchmarks, tide gauges, and buoys. DORIS is the geodetic technique with the most homegenous station distribution, implementation, and operation (Fagard 2006). Connections between the techniques are enabled by collocation at a subset of ITRF sites where two or more space geodesy instruments are operated and local-site ties between monuments are measured using terrestrial high-precision surveying techniques (Figure 9.5). Conventional precise surveying techniques have been used for decades to connect different techniques, and precise leveling is still a critical method for establishing the vertical tie between tide gauges and local benchmarks.

None of the space geodesy techniques is able to provide all the necessary parameters for the TRF datum definition (origin, scale, and orientation). While satellite techniques are sensitive to the Earth center of mass (a natural TRF origin; the point around which a satellite orbits), VLBI (whose TRF origin is arbitrarily defined through some mathematical constraints) is not. The scale is dependent on the modeling of some physical parameters, and the absolute TRF orientation (unobservable by any technique) is arbitrarily or conventionally defined through specific constraints. The utility of multitechnique combinations is therefore recognized for reference-frame determination, and in particular for accurate datum definition.

Since the creation of the IERS in 1987, the implementation of the ITRF has been based on multitechnique combination, incorporating individual TRF solutions derived from space geodesy techniques as well as local ties at co-located sites. In principle, the particular strengths of one observing method can compensate 


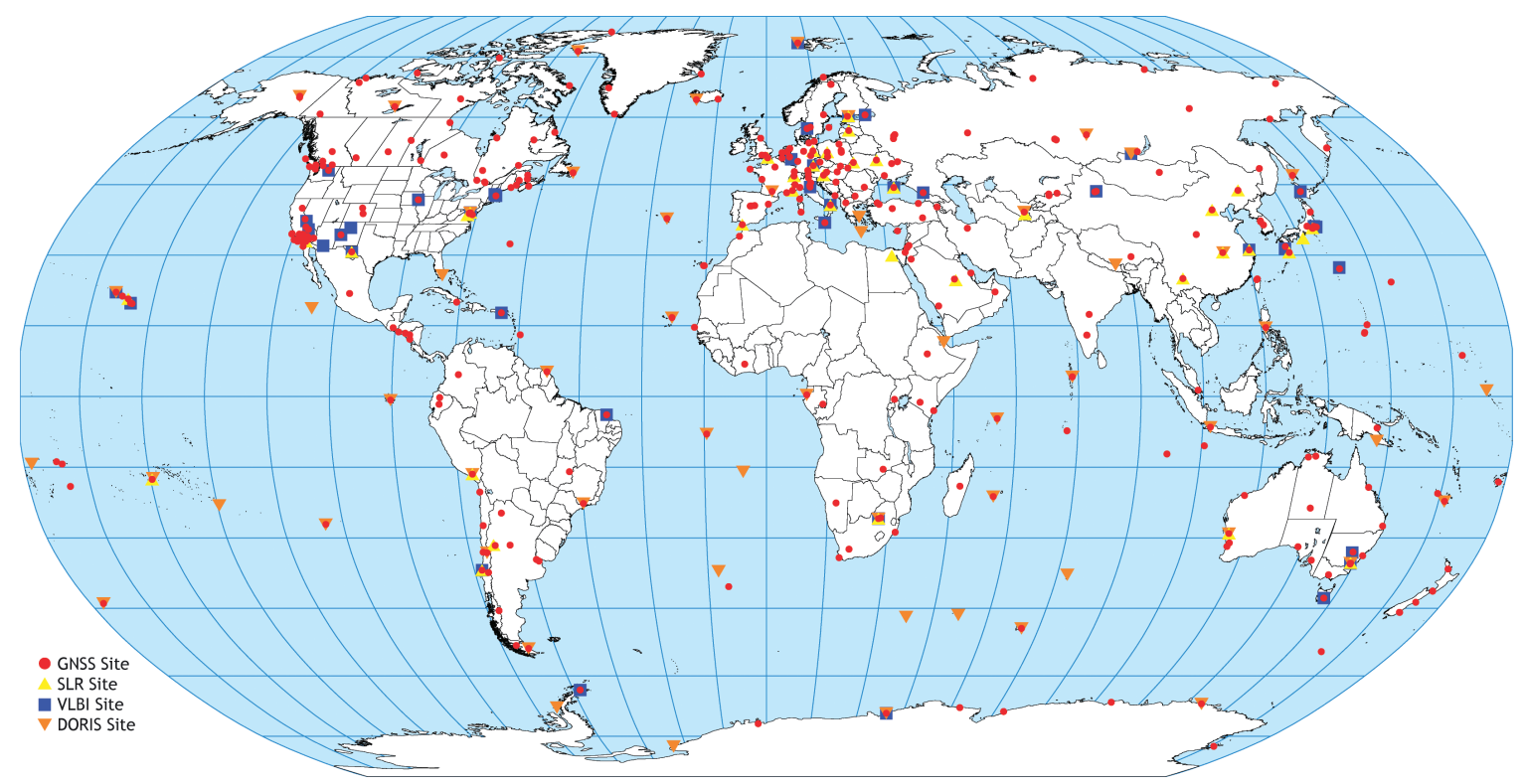

Figure 9.5 Current distribution of geodetic networks: GNSS, SLR, VLBI, and DORIS. (Courtesy of C. Noll 2008.)

for weaknesses in others if the combination is properly constructed, suitable weights are found, and accurate local ties at co-located sites are available. The ITRF quality suffers from any network degradation over time because it is heavily dependent on the network configuration. To cite only one pertinent network issue, the current configuration of co-located sites as depicted in Figure 9.6 is far from an optimal even global distribution. In particular, sites with three co-located geodetic techniques are fewer than 20 and with four techniques there are only two.

Over a decade, the stability of the ITRF2000 geocentric origin (defined by SLR) is estimated to be at the few-millimeter level and the accuracy of its absolute scale (defined by SLR and VLBI) is around $0.5 \mathrm{ppb}$ (equivalent to a shift of approximately $3 \mathrm{~mm}$ in station heights) (Altamimi et al. 2002). While SLR currently provides the most accurate realization of the Earth's long-term center of mass for the ITRF origin, estimates of geocenter motion still need to be improved by the analysis centers of all satellite techniques. From ITRF2000 results it was found that the best scale agreement was between VLBI and SLR solutions. Geocenter stability depends on accurate dynamic modeling and observation of geodetic satellites, such as SLR and GNSS (Tregoning and van Dam 2005). Scale stability might be better ensured by minimizing source-related errors, which would imply VLBI, but it also requires accurate tropospheric delay modeling, which would imply SLR (because of the observed frequencies, the tropospheric delay effects are considerably smaller in SLR observations than in either VLBI or GNSS), so some combination of VLBI and SLR is likely to be required. The expected increase in 


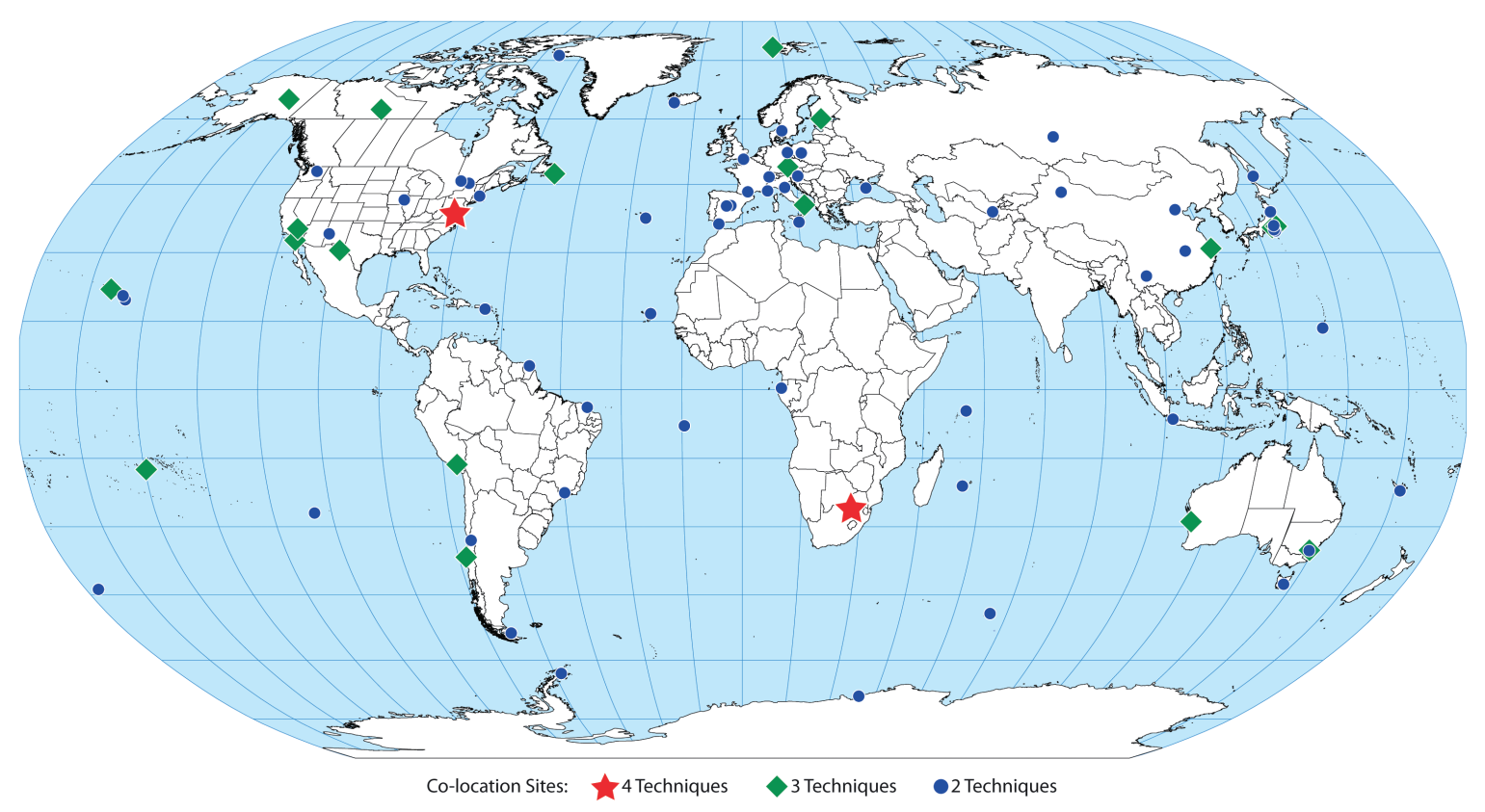

Figure 9.6 Current distribution of co-located space geodesy sites. (Courtesy of Z. Altamimi.)

numbers of GNSS satellites over the next decade to approximately 100 suggests the strong potential of GNSS to contribute significantly to both geocenter and scale stability.

Since the mid-1990s, initiated first by the IGS (Dow et al. 2005), several technique-specific analysis centers started to publish time series of daily or weekly solutions of station positions and daily Earth Orientation Parameters (EOPs). The methodology has since been extended to combine time series of results (Altamimi et al. 2005) and to extract all the benefits offered by time series combinations; for instance, detecting and monitoring non-linear station motions and other kinds of discontinuities in the time series: site instabilities, earthquake-related dislocations, seasonal loading effects, etc. Time-series combination also allows EOPs to be treated in a fully consistent way; that is, to rigorously ensure the alignment of EOPs to the combined frame. Unlike the previous ITRF solutions, ITRF2005 is based on the analysis and combinations of such time series of station positions and EOPs (Altamimi et al. 2007). The new ITRF2008 is currently under preparation and is expected to be released in 2010 .

\subsubsection{Errors Related to Reference Systems and their Effects}

The following three aspects of reference systems lead to uncertainty in the position of a physical point that should be considered in addition to the observational error in position: 
1 error in physical aspects of the conventions, in particular, the motion model;

2 error in the alignment of the frame that is used to realize the reference system; and

3 error in coordinates of the reference frame that have been used to position the points of interest.

For the challenge of understanding sea-level variation, the following issues relate to the above errors. First, the solid Earth's surface (including the ocean bottom) moves much like the sea surface itself, in the sense that it has tides $(\approx 30 \mathrm{~cm})$. Some of the motion is predictable, such as tidal motion, much of the short-period motion tends to average out in the long-term, and some of the motion is unpredictable or imprecisely known. On the timescale of a century, motion of the Earth's surface can be of the same order of magnitude as motion of the sea surface $(0.1 \mathrm{~m})$ and locally can exceed this by a significant amount. Naturally the problem of the impact of sea-level variations requires consideration of the land motion. A tide gauge directly measures the displacement of the sea surface relative to land at a point, and so would seem ideal. However, the use of tide-gauge data alone to infer global measures of sea-level change is fundamentally problematic due to sample bias of the relative motions of the sea surface and land over a broad range of spatial and temporal scales. Processes such as GIA have been given considerable attention and are addressed elsewhere in this book. The land beneath tide gauges may be forced to move by processes unique to (or more biased at) coastlines (versus deep ocean floors), such as coastal erosion, sedimentary loading, subsidence, atmospheric loading, anthropogenic activities, tectonic processes (e.g. strain accumulation at locked subduction zones along much of the western coasts of the Pacific rim and Sumatra), and the different ocean/land response to present-day mass redistributions such as cryospheric loading and terrestrial hydrologic loading. Other considerations include the stability of the structures to which tide gauges are attached, and the local stability of the land beneath. In general, coastlines are well known to host unique oceanic processes that can bias sea level; however, a crucial point is that this is also true for the land near the coast, in that coastlines provide a very poor sample distribution of Earth deformation processes that will not generally tend to average out on the global scale.

Second, currently, the possibility of an error in the tie of the reference frame origin to the Earth's center of mass at the 1-2 mm/year level, or an error in scale rate at the level of $0.1 \mathrm{~mm} /$ year, cannot be dismissed. An error in the realization of the reference frame origin at the center of mass of the solid Earth implies an error in the height of the sea surface inferred by satellite altimetric observations with very-long-wavelength (hemispheric-scale) correlated errors (Figure 9.4). If the error happened to point in the direction of large oceans such as the Pacific Ocean, this could give the erroneous impression of global sea-level change. More generally, the degree- 1 terms of the spherical harmonic expansion of the ocean function imply a direct correlation of errors between realization of the origin (with time) and global mean-sea-level variation. Specifically, errors in the velocity 
of the origin at the level of $2 \mathrm{~mm}$ /year will map into global mean-sea-level errors by as much as $0.4 \mathrm{~mm} /$ year (Kierulf and Plag 2006). This is as large as the physical contributions of mass exchange and thermal expansion. An error in scale rate will appear as a secular change in the height of ocean altimeters, thus giving the erroneous impression of global change in sea surface height. Tide gauge measurements are immune to reference frame problems and despite the problems with sampling bias and possible land movements, they do provide a measure of ground truth that can be useful for comparison with satellite altimeter measurements.

Third, as reference systems are updated because of improved conventions or improved frames (using more recent measurements and models), the entire time series of coordinates of a monitored station will change. Even the sign of vertical velocity can change. Therefore, the concept of "measuring and archiving" the heights of tide gauges should be abandoned. The heights of stations cannot be measured absolutely, and the entire time series are always going to be subject to changes and reanalysis as reference frames continue to be updated, and certainly improved.

\subsubsection{Challenges and Future Requirements}

From a reference-frame perspective, the challenge for monitoring long-term variability in sea level is to define the frame origin and scale with greater accuracy than the signal to be estimated. This requires a frame stability of $0.1 \mathrm{~mm} /$ year, and scale stability of $0.01 \mathrm{ppb} /$ year. These requirements would reduce the framerelated bias to the level of a few percentage points of the total effect of sea-level change. Current errors may be about a factor of 10 larger than this, although the level of errors are currently difficult to assess.

The most critical TRF parameters of interest to mean-sea-level studies are the origin and the scale and their long-term stability. For example, any scale bias in the TRF definition propagates directly to the height component of the stations and vice versa. As the ITRF relies on SLR to define its origin and on SLR and VLBI for its scale, the importance of these two techniques should not be underestimated for the ITRF accuracy and stability over time. Unfortunately, the distribution of the current SLR and VLBI networks and their co-locations is poor and worsening over time, threatening the long-term ITRF stability. To give a simple example, from the ITRF2005 analysis, the estimated impact of the poorly distributed SLR network and its co-locations with the other techniques induces a scale bias of about $1 \mathrm{ppb}$ and $0.1 \mathrm{ppb} /$ year. This is a large effect by itself and about 10 times larger than the science requirement to address sea-level change.

To meet these challenges and future requirements, the geodetic networks must be well distributed, maintained, and improved to provide the fundamental context for understanding sea-level change. 


\subsection{Linking GPS to Tide Gauges and Tide-Gauge Benchmarks}

\subsubsection{Tide Gauges and the Reference Frame}

Tide gauges measure sea-level changes as variations in the relative position between the crust and the ocean surface. These measurements are difficult to interpret because they are influenced by several phenomena inducing vertical crustal movements. Vertical crustal motions at tide gauges can be measured to high accuracy independently of the sea-level reference surface by means of space geodetic techniques such as GPS and DORIS (Soudarin et al. 1999); therefore, it is possible to separate the crustal motions from geocentric sea-level variations. Tide-gauge measurements are difficult to compare because tide gauges are referred to local reference systems not yet connected on a common global datum. However, it should be pointed out that several international efforts are underway both at global (IOC 1997) and regional scales (Zerbini et al. 1996; Becker et al. 2002) which aim to overcome this challenge.

Continuous GPS is the technique of choice in vertical crustal motion determination due to the ease of use, high precision, and its direct connection to the ITRF through the products of the IGS. Simultaneous GPS measurements performed at tide gauges and at fiducial reference stations of the global reference frame can be tied in a global well-defined reference frame. The possibility to refer the tidegauge data to the same high-precision global reference system allows comparison between the different tide-gauge data sets. This was not the case until before 1995 when tide-gauge benchmark coordinates were mostly available in the different national height systems (Wöppelmann et al. 2006).

In order to determine long-term height changes due to vertical crustal movements it is necessary to correct the GPS measurements for seasonal oscillations which can corrupt the estimate of the long-term trends up to a few millimeters per year. Loading components due to seasonal variations of the atmosphere, hydrology, and non-tidal oceanic effects (Blewitt et al. 2001; van Dam et al. 2001; Zerbini et al. 2004) have been recognized as major contributors to the observed seasonal oscillations in GPS time series. Concerning non-tidal oceanic effects, recent studies at the global and regional level (Chao et al. 2003; Zerbini et al. 2004) show that modeled bottom-pressure amplitudes taken from the Estimating the Circulation and Climate of the Ocean (ECCO) project are a factor of two smaller than those observed. Furthermore, deficiencies in the physical models can create spurious periodic effects including annual and semi-annual signals. Penna and Stewart (2003) show how mismodeled short-period tides (semidiurnal and diurnal) can alias into height time series, and Stewart et al. (2005) showed how truncation of the observation model - and even the arbitrary choice of processing data in 24-hour segments - causes similar propagation effects. Penna et al. (2006) demonstrated that mismodeled (sub-)daily periodic signals in horizontal coordinates can propagate into periodic signals in the vertical component, sometimes 
with an admittance greater than 100\%. Boehm et al. (2006) showed that deficiencies in the Niell mapping function (used to relate the tropospheric delay in the zenith direction to the delay at any elevation angle) causes season-dependent height errors of up to $10 \mathrm{~mm}$, in particular in the Southern Hemisphere. Tregoning and Herring (2006) showed that the use of actual observed atmospheric pressure values - rather than a standard sea-level atmospheric pressure model - for computing the a priori zenith hydrostatic delay reduces season-dependent height errors and hemisphere-dependent biases in height estimates. Watson et al. (2006) showed how improvements in the modeling of the solid Earth tides have reduced the annual signals in global GPS analysis, with the implication being that any errors in the model currently used in all space-geodetic techniques can be expected to contribute to seasonal variations that still remain in geodetic height time series.

The accuracy required by GPS to monitor tide-gauge benchmark positions on shorter timescales requires more accurate GPS positions, which in turn requires advances in network and observational configurations and geodetic data analyses. The IGS is intent on continuing to improve the accuracy of its GNSS products and, in collaboration with sister services, to strive towards meeting the demanding requirements of these longer-term studies. (http://igs.org/components/prods. html; Altamimi et al. 2002; Dow et al. 2005).

Independently from space geodetic techniques, an alternative approach to monitoring site velocities is provided by the measurement of absolute gravity at tide-gauge benchmarks. Absolute gravity does not directly estimate the vertical displacement of the crust, as gravity is affected both by mass in the ocean itself and the processes responsible for vertical crustal movement. If the processes are well understood, then it can provide independent confirmation of GPS results, particularly at inland sites (Zerbini et al. 1996; Becker et al. 2002; Teferle et al. 2006).

\subsubsection{Tide-Gauge Measurements: Historical Perspective}

For more than a century tide-gauge measurements in estuaries or coastal shorelines have been widely used for monitoring local sea or estuary levels, for navigation and port operations, for assimilation into tide models for scientific research and water-quality applications and for use with storm surge models for flood warning. The tide-gauge systems are or have been operated by port authorities or national maritime services with a high level of accuracy and reliability. Since 1933, the Permanent Service for Mean Sea Level (PSMSL), one of the oldest scientific services noted in other chapters in this book, has been responsible for the collection, publication, analysis, and interpretation of sea-level data from the global network of tide gauges (Woodworth and Player 2003). From the geodetic point of view, the tide-gauge system, in particular the tide-gauge zero or pole staff, is precisely leveled by conventional precise surveying techniques to a primary tidegauge benchmark surrounded by and tied to several distant secondary benchmarks. In addition, most of the tide gauges are connected to the first-order 
national height system. All benchmarks should be leveled on a regular basis to ensure the long-term stability of the height reference (IOC 2006).

Recently, in the public and scientific climate discussions, data from tide gauges is increasingly important in providing long-term and reliable measures of the sea level. Here, the tide-gauge measurements are used as a primary input to study changes in local mean sea level, tidal amplitudes, surge statistics, and as boundary conditions in oceanographic circulation models. They also act as ground truth for, for example, satellite radar altimetry (SRALT). Tide gauges also help to define the global height system, and many national datums, both historically and even currently, refer their vertical measurements to "mean sea level".

An increasing number of tide-gauge benchmarks have been equipped with continuously operating GPS receivers. A small number of these stations are part of the global IGS network, and many more stations contribute to local or regional networks. There is increasing demand from the international observing systems (i.e. Global Climate Observing System (GCOS), Global Ocean Observing System (GOOS), and Global Sea Level Observing System (GLOSS)) for continuous provision of highly precise GPS height time series with an accuracy of better than $1 \mathrm{~mm} /$ year. An affirmed objective of the GLOSS group is to have a GPS receiver at every GLOSS Core Network station.

\subsubsection{The TIGA Pilot Project}

At present, about 280 tide-gauge stations are known to have continuous operating GPS stations within $10 \mathrm{~km}$ (Figure 9.7) (Wöppelmann et al. 2006). This number of stations is far too high for current IGS analysis centers to process, although schemes are under development for routine analysis of up to an order of magnitude more stations by 2010. In addition, the current IGS accuracy does not fully meet the requirements of the sea-level community as there is insufficient station coverage and need for improved accuracy of the vertical component.

In response to the demands by the scientific community, the IGS in 2001 initiated the GPS Tide Gauge Benchmark Monitoring Pilot Project (TIGA-PP). The pilot project includes analyzing GPS data from stations at or near public tide gauges on a continuous basis (known as cGPS@TG, for continuous GPS at tide gauges). The primary objectives of the TIGA-PP are to promote, establish, maintain, and expand a high-quality global cGPS@TG network and to compute precise daily or weekly station coordinates and velocities for this network. This goal is achieved by processing a large number of stations and also by reprocessing older data sets. TIGA-PP, as an IGS project, relies on the IGS network infrastructure, the processing capability, and expertise of the IGS community and is supported by GLOSS and PSMSL for the tide-gauge component.

The primary product is weekly sets of coordinates for analyzing vertical motions of tide gauges and tide-gauge benchmarks. All products are made publicly available to support and encourage other applications, for example sea-level studies. In particular, the products of the service facilitate the distinction between absolute 


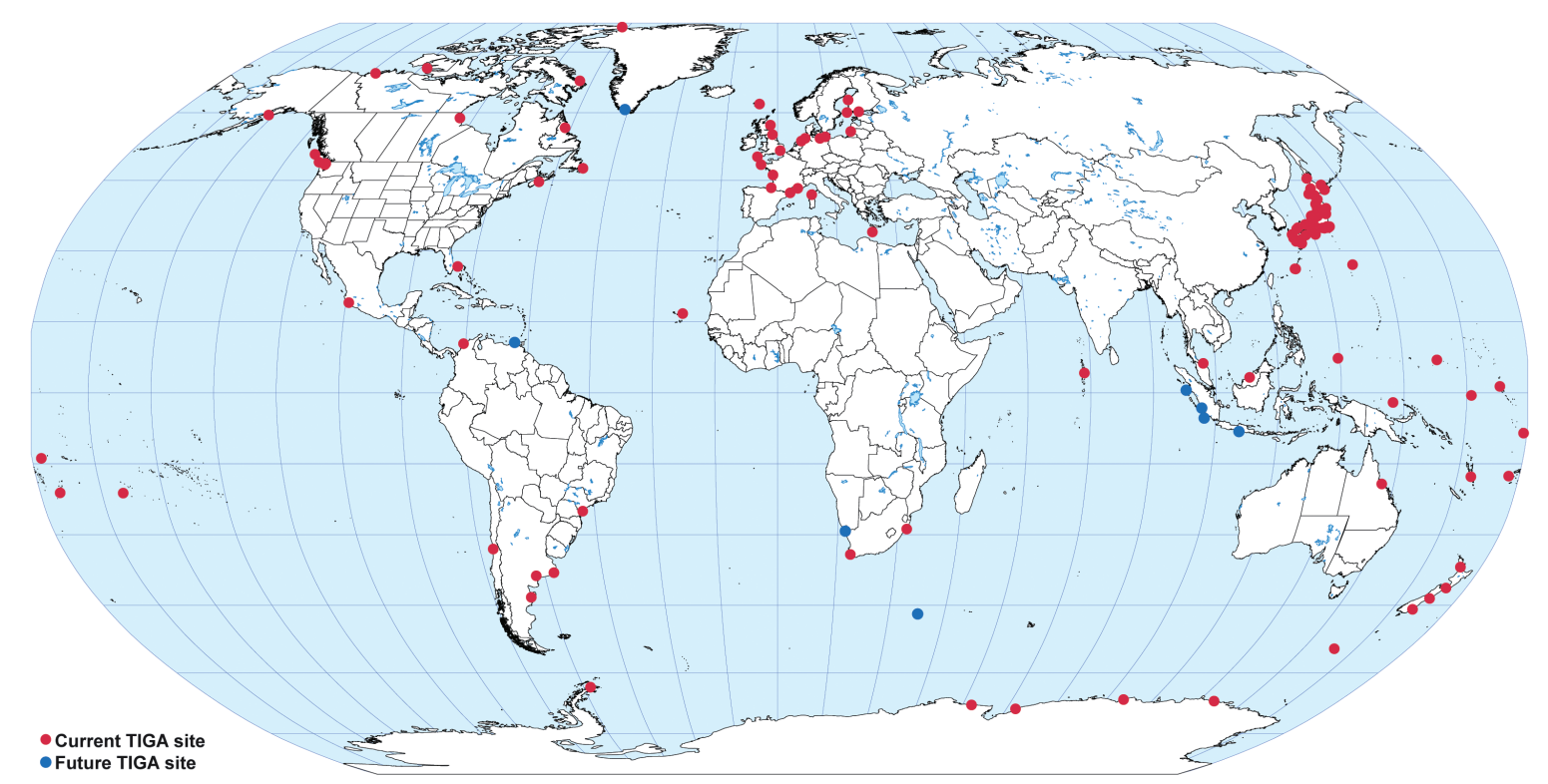

Figure 9.7 Current network of GPS stations at tide gauges contributing to the TIGA Pilot Project. (Courtesy of C. Noll 2008.)

and relative sea-level changes by accounting for the vertical uplift of the station and are, therefore, an important contribution to climate-change studies. TIGA processing may further contribute to the calibration of satellite altimeters and other oceanographic activities.

\subsubsection{Current Status of TIGA}

The IGS has very strict requirements on data quality and availability, and latency in data delivery of network stations. In contrast to the tide-gauge station networks, the GPS network coverage appears to be reasonably balanced geographically, with the exception of the African continent. Therefore, many of the GPS tide-gauge stations important for sea-level research are not part of the IGS network either for geographical reasons (too close to existing stations already in the IGS network) or because of latency in data provision (remote stations with poor data communications). TIGA analysis incorporates these tide-gauge GPS stations not included in IGS global analyses.

The tide-gauge stations contributing to TIGA must have a high level of reliability. One prerequisite for stations to be included in the TIGA networks is the public availability of the tide-gauge data at GLOSS data centers. Preferably, the stations are equipped with a primary GPS on or near the tide gauge and a secondary GPS station, inland (IOC 2006). Maintenance of the equipment should be repeated on a regular basis, including first-order leveling to all the available 
benchmarks (which is often difficult to accomplish due to increasingly limited geodetic surveying resources and capabilities).

It is imperative that the relative vertical movement between the tide gauges (and/or tide gauge benchmarks) and the nearby GPS stations is known to a higher accuracy than either the accuracy of the GPS vertical velocities or the tide-gauge estimates of relative sea-level; otherwise, the measurement of the connection between the two systems becomes the limiting factor on the overall accuracy. To observe a height tie with an accuracy of less than $0.5 \mathrm{~mm}$ over a distance of up to $10 \mathrm{~km}$ is a challenge even for the highest-precision leveling. An alternate approach that could be considered for the future is InSAR, where theoretical and experimental accuracies of velocity estimates from the permanent scatterers technique is $0.1-0.5 \mathrm{~mm} /$ year (Colesanti et al. 2003).

Data from GPS stations co-located at 102 tide gauges are processed on a regular basis by TIGA analysis centers (TACs). Other GPS stations complement this network to define a common reference frame. Currently six TACs process TIGA GPS on a best-effort basis. In addition, a reanalysis of past data is performed, leading to a homogeneous data set. TIGA is providing solutions with a latency of at least 460 days to permit the high-latency data from remote and manually operated stations to be included in the analysis. The TACs use almost identical processing and analytical strategies as the IGS Analysis Centers, so that the reanalysis solutions are comparable. The reprocessed past solutions are less affected, for example, by software changes, changes in the processing strategies and correction models, or station hardware failures not immediately detected. In the more recent years, additional cGPS@TGs were included in the TIGA network; thus, the reprocessing itself also needs to be repeated frequently to process newly available data.

Initial tests are being performed to combine the different solutions from the TACs. Due to TAC processing on a best-effort basis, a complete set of solutions is available only for selected weeks. In addition, complementary studies are being carried out, to identify and remove undetected jumps in station time series, or test the strategies for a TIGA dedicated combination strategy. Based on this experience, the individual TAC solutions will be improved and when necessary reprocessed. In particular, the combination of the individual solutions will be updated frequently to incorporate new stations and new solutions and to always use the newest correction models, for example from atmospheric pressureloading models.

\subsubsection{Steps for Taking TIGA Forward}

There are a number of actions that can be taken to improve TIGA.

- Promote the establishment and maintenance of high-quality ties between tidegauge and GPS stations and their benchmarks.

- Promote the establishment of dual GPS receivers (two closely located receivers) for high-quality cGPS@TG monitoring stations. 
- Encourage prescise ties of tide-gauge benchmarks and nearby geodetic markers by continuous GPS, first-order leveling on a regular basis, or permanent-scatterers InSAR.

- Establish a common database of known or possible jumps in GPS and tidal time series.

- Study loading effects of shore- or island-based cGPS@TG points versus inland GPS stations.

- Study secondary ocean-loading effect caused by changes in ocean level.

- Study the effects in the height component by the combination of TIGA stations with the global geodetic reference system.

- Study the use of consistent loading corrections in TIGA processing (e.g. apply atmospheric loading corrections during the processing or during the combination of multiple analysis solutions).

\subsection{Recommendations for Geodetic Observations}

The ITRF must be more robust and stable over multidecadal timescales. The target accuracy is $0.1 \mathrm{~mm} /$ year in the realization of the center of mass of the entire Earth system ("geocenter stability"), and $0.01 \mathrm{ppb} /$ year in scale stability. Geocenter stability depends on accurate dynamic modeling and observation of geodetic satellites, such as SLR and GNSS. Scale stability might be better ensured by minimizing source-related errors, which would imply VLBI, but it also requires accurate tropospheric delay modeling, which would imply SLR (because of the observed frequencies, the tropospheric delay effects are considerably smaller in SLR observations than in either VLBI or GNSS). Some combination of VLBI and SLR is likely required. The increase in GNSS satellites over the next decade to approximately 100 suggests the strong potential of GNSS to contribute significantly to both geocenter and scale stability.

The highest stability requires strong connections between the reference frames of the various geodetic systems. It is recommended to:

- implement more high-quality sites of every technique with a good (even) global distribution, and upgrade existing sites to keep pace with technological developments;

- co-locate VLBI and SLR wherever possible, and require GPS/GNSS instrumentation at every VLBI and SLR site;

- sustain and improve financial support for the technique-specific scientific services and their critical components, from infrastructure to analyses (i.e. IERS, IGS, IVS, ILRS, IDS, PSMSL, IGFS);

- place laser retroreflectors on all future GNSS satellites, and undertake research to improve laser-ranging effectiveness to Medium Earth Orbiters (MEOs);

- research biases between the various techniques, types of satellite, and instrumentation;

- improve tropospheric delay models; and

- support GGOS as the new paradigm for integrating space geodetic techniques. 
To ensure long-term stability and consistency in the measurements of sea level by altimetry and space gravity missions (e.g. GRACE), it is recommended that (1) missions similar to the current altimeter and gravity missions should be continued indefinitely with sufficient overlap between missions (an overlap period of at least one year to avoid any gap between missions), and (2) a world vertical datum be established, possibly based on a precise, high-resolution global geoid model, to which all elevation-type measurements should be referred (unification of national and regional vertical datums). This will require international agreements for free exchange of gravimetric, altimetric, elevation, and other relevant data, and collaborative research work to integrate satellite, terrestrial, and airborne gravity and gradiometer data, which could be undertaken under the auspices of GGOS.

Tide gauges should be monitored for height variations using continuous GPS systems installed directly at the tide gauge. This could be accomplished by expanding efforts such as the TIGA project within IGS and by encouraging expansion of related regional activities within GLOSS. In order to have a uniform distribution of tide gauges around the globe, additional tide gauges co-located with GPS, will have to be installed in areas with poor tide-gauge coverage.

It is only through physical models that progress can be made toward understanding measurements of sea-level variability. It is recommended that research and development of comprehensive Earth models evolve in order to assimilate all geodetic data types (and including tide-gauge data) that are relevant to determining sea-level change. Such models must be self-consistent both gravitationally and with respect to the conservation of mass. At the first level, models integrating geodetic data must be developed. At the next level, the models should be integrated with terrestrial hydrological models, cryospheric models, and ocean/ atmospheric circulation models.

Finally, in order to achieve the goal of determining sea-level changes at the level of $0.1 \mathrm{~mm} /$ year, financial support for the recommended systems and research activities must be brought up to a level capable of meeting that goal, and the support must be sustained for decades, at the very least. This requires commitments that go beyond the current typical relationships between government funding agencies and science programs. It is recommended that United Nations Educational, Scientific and Cultural Organization (UNESCO)/IOC, and elements of the former Integrated Global Observing Strategy-Partnership (IGOS-P) Coastal Zone Theme, together with the funding agencies, assess what is required by their organizations to make the funding system work for programs requiring such long-term commitment. Agreements should be sought at the international level to ensure global-scale international commitment toward solving a globalscale international problem. As a first step toward this goal, the importance of the reference frame for sea level in particular, and Earth observation in general, should be recognized by the Group on Earth Observations (GEO) as a crosscutting activity that affects all benefit areas addressed within GEO's Global Earth Observation System of Systems (GEOSS) (http://www.earthobservations.org/ index.html). 


\section{Acknowledgments}

GB acknowledges support by NASA/IDS grant NNG04G099G and NASA/SENH grant NAG5-13683. Some of the research described in this chapter was carried out at the Jet Propulsion Laboratory, California Institute of Technology, under a contract with the National Aeronautics and Space Administration.

\section{References}

Altamimi Z., Sillard P. and Boucher C. (2002) ITRF2000: a new release of the International Terrestrial Reference Frame for earth science application. Journal of Geophysical Research 107(B10), 2214.

Altamimi Z., Boucher C. and Willis P. (2005) Terrestrial reference frame requirements within GGOS perspective. Journal of Geodynamics 40, 363-74.

Altamimi Z., Collilieux X., LeGrand J., Garyt B. and Boucher C. (2007) ITRF2005: a new release of the International Terrestrial Reference Frame based on time series of station positions and Earth Orientation Parameters. Journal of Geophysical Research V 112, B09401.

Becker M., Zerbini S., Baker T., Bürki B., Galanis J., Garate J. et al. (2002) Assessment of height variations by GPS at Mediterranean and Black Sea coast tide gauges from the SELF Projects. Global and Planetary Change 34, 5-35.

Beutler G. (2005) Methods of Celestial Mechanics, vols I and II. Springer, Berlin.

Blewitt G. (2003) Self-consistency in reference frames, geocenter definition, and surface loading of the solid Earth. Journal of Geophysical Research 108(B2), 2103.

Blewitt G. and Clarke P. (2003) Inversion of Earth's changing shape to weigh sea-level in static equilibrium with surface mass redistribution. Journal of Geophysical Research 108(B6), 2311.

Blewitt G., Lavallee D., Clarke P. and Nurutdinov K. (2001) A new global mode of Earth deformation: seasonal cycle detected. Science 294, 2342-5.

Boehm J., Niell A., Tregoning P. and Schuh H. (2006) Global Mapping Function (GMF): a new empirical mapping function based on numerical weather model data. Geophysical Research Letters 33, L07304.

Chao B., Au A.Y., Boy J.-P. and Cox C.M. (2003) Time-variable gravity signal of an anomalous redistribution of water mass in the extratropic Pacific during 1998-2002. Geochemistry Geophysics Geosystems 4, 1096.

Chelton D., Ries J.C., Haines B.J., Fu L.-L. and Callahan P.S. (2001) Altimetry. In Satellite Altimetry and Earth Sciences (Fu L.-L. and Cazenave A., eds). Academic Press, New York.

Colesanti C., Ferretti A., Novali F., Prati, C. and Rocca F. (2003) SAR monitoring of progressive and seasonal ground deformation using the Permanent Scatterers technique. IEEE Transactions on Geoscience and Remote Sensing 41, 1685-1701. 
Crétaux J.-F. and Birkett C. (2006) Lake studies from satellite altimetry. Comptes Rendus Geoscience 338(14-15), 1098-1112.

Dow J., Neilan R.E. and Gendt G. (2005) The International GPS Service: celebrating the 10th anniversary and looking to the next decade. Advances in Space Research 36, 320-6.

Drewes H. (ed.) (2005) The Global Geodetic Observing System. Journal of Geodynamics 40, 355-6.

Fagard H. (2006) Twenty years of evolution for the DORIS permanent network: from its initial deployment to its renovation. In: DORIS Special Issue (Willis P., ed.). Journal of Geodesy 80, 429-56.

Forsberg R., Sideris M.G. and Shum C.K. (2005) The gravity field and IGGOS. Journal of Geodynamics 40, 387-93.

Fu L.-L. and Chelton D.B. (2001) Large-scale ocean circulation. In: Satellite Altimetry and Earth Sciences: a Handbook for Techniques and Applications (Fu L.L. and Cazenave A., eds), pp. 133-69. Academic Press, San Diego.

Haines B., Bar-Sever Y., Bertiger W., Desai S. and Willis P. (2004) One-centimeter orbit determination for Jason-1: New GPS-based strategies Marine Geodesy 27, 299-318.

IOC (1997) Global Sea-level Observing System (GLOSS) Implementation Plan1997. Intergovernmental Oceanographic Commission Technical Series, No. 50. UNESCO, Paris.

IOC (2006) Manual on Sea-Level Measurement and Interpretation. Volume 4-An Update to 2006 (Aarup T., Merrifield M., Perez B., Vassie I. and Woodworth P., eds). Intergovernmental Oceanographic Commission Manuals and Guides, no. 14. IOC, Paris.

Kierulf H.P. and Plag H.-P. (2006) Precise point positioning requires consistent global products. In: EUREF Publication No. 14 vol. BKG 35 of Mitteilungen des Bundesamtes für Kartografie und Geodäsie BKG (Torres J.A. and Hornik H., eds), pp. 111-20. BKG, Frankfurt am Main.

Kovalevsky J., Mueller I. and Kolaczek B. (eds) (1989) Reference Frames in Astronomy and Geophysics. Astrophysics and Space Science Library, vol. 154. Springer, New York.

Kuo C.Y., Shum C.K., Yi Y., Braun A., Schroeter J. and Wenzel M. (2006) Determination of $20^{\text {th }}$ century global sea-level rise. Geophysical Research Abstracts 6, 07741.

Luthcke S.B., Zelensky N.P., Rowlands D.D., Lemoine F.G. and Williams T.A. (2003) The 1-centimeter orbit: Jason-1 precision orbit determination using GPS, SLR, DORIS and altimeter data. Marine Geodesy, Special Issue on Jason-1 Calibration/Validation Part 1 26(3-4), 399-421.

McCarthy D.D. and Petit G. (eds) (2003) IERS Conventions. IERS Technical Note No. 32. International Earth Rotation Service, Frankfurt am Main.

Pearlman M.R., Degnan J. and Bosworth J. (2002) The International Laser Ranging Service. Advances in Space Research 30(2), 135-43.

Penna N.T. and Stewart M.P. (2003) Aliased tidal signatures in continuous GPS height time series. Geophysical Research Letters 30(23), 2184. 
Penna N.T., King M.A. and Steward M.P. (2006) GPS height time series: short period origins of spurious long period signals. Journal of Geophysical Research 112, B02402.

Plag H.-P. (2005) The GGOS as the backbone for global observing and local monitoring: a user driven perspective. Journal of Geodynamics 40, 479-86.

Plag H.-P. (2006) National geodetic infrastructure: current status and future requirements - the example of Norway. Nevada Bureau of Mines and Geology, Bulletin 112.

Rummel R., Rothacher M. and Beutler G. (2005) Integrated Global Geodetic Observing System (IGGOS) - science rationale. Journal of Geodynamics 40, 357-62.

Schlüter W., Himwich E., Nothnagel A., Vandenberg N. and Whitney A. (2002) IVS and its important role in the maintenance of the global reference systems. Advances in Space Research 30(2), 145-50.

Schutz B.E., Zwally H.J., Shuman C.A., Hancock D. and DiMarzio J.P. (2005) Overview of the ICESat mission. Geophysical Research Letters 32, L21S01.

Seeber G. (2003) Satellite Geodesy - Foundations, Methods, and Applications, pp. 500-5. Walter de Gruyter, Berlin.

Soudarin L., Crétaux J.F. and Cazenave A. (1999) Vertical crustal motions from the DORIS space-geodesy system. Geophysical Research Letters 26(9), 1207-10.

Stewart M.P., Penna N.T. and Lichti D.D. (2005) Investigating the propagation mechanism of unmodelled systematic errors on coordinate time series estimated using least squares. Journal of Geodesy 79(8), 479-89.

Tapley B.D., Bettadpur S., Ries J.C., Thompson P.F. and Watkins M.M. (2004) GRACE measurements of mass variability in the Earth system. Science 305, 503-5.

Tavernier G., Fagard H., Feissel-Vernier M., Le Bail K., Lemoine F., Noll C. et al. (2006) The International DORIS Service: genesis and early achievements. Journal of Geodesy 80, 403-17.

Teferle F.N., Bingley R.M., Williams S.D.P., Baker T.F. and Dobson A.H. (2006) Using continuous GPS and absolute gravity to separate vertical land movements and changes in sea level at tide gauges in the UK. Philosophical Transactions of the Royal Society of London A 364, 917-30.

Tregoning P. and van Dam T.M. (2005) Effects of atmospheric pressure loading and seven-parameter transformations on estimates of geocenter motion and station heights from space geodetic observations. Journal of Geophysical Research 110, B03408.

Tregoning P. and Herring T.A. (2006) Impact of a priori zenith hydrostatic delay errors on GPS estimates of station heights and zenith total delays. Geophysical Research Letters 33, L23303.

van Dam T.M., Wahr J., Milly P.C.D., Shmakin A., Blewitt G., Lavallée D. and Larson K. (2001) Crustal displacements due to continental water loading. Geophysical Research Letters 28(4), 651-4. 
Watson C., Tregoning P. and Coleman R. (2006) The impact of solid Earth tide models on GPS coordinate and tropospheric time series. Geophysical Research Letters 33, L08306.

Watts R.C. and Morantine M.C. (1991) Is the greenhouse gas-climate signal hiding in the deep ocean? Climatic Change 18(4), iii-vi.

Woodworth P.L. and Player R. (2003) The Permanent Service for Mean Sea Level: an update to the $21^{\text {st }}$ century. Journal of Coastal Research 19, 287-95.

Wöppelmann G., Zerbini S. and Marcos M. (2006) Tide gauges and geodesy: a secular history of interactions and synergies. Comptes Rendus Geosciences 338(14-15), 980-91.

Zerbini S., Plag H.-P., Baker T., Becker M., Billiris H., Bürki B. et al. (1996) Sealevel in the Mediterranean: a first step towards separating crustal movements and absolute sea-level variations. Global and Planetary Change 14(1-2), 1-48.

Zerbini S., Matonti F., Raicich F., Richter B. and van Dam T. (2004) Observing and assessing non-tidal ocean loading using ocean, continuous GPS and gravity data in the Adriatic area. Geophysical Research Letters 31, L23609. 